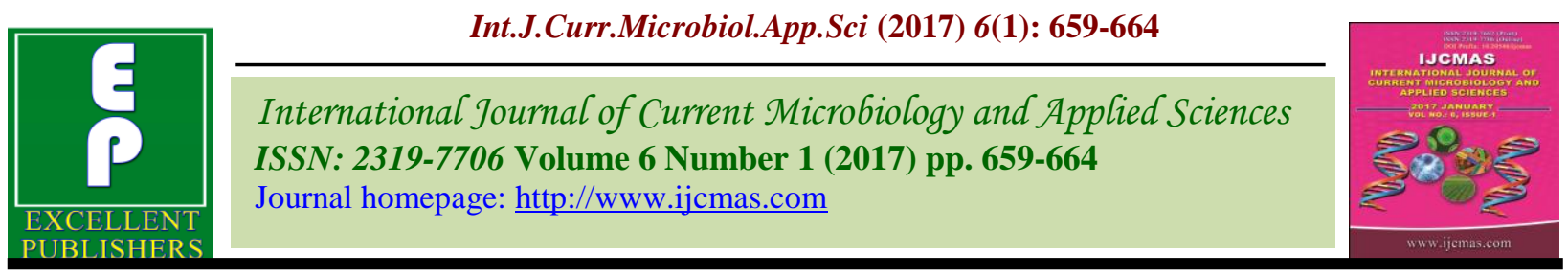

Original Research Article

http://dx.doi.org/10.20546/ijcmas.2017.601.079

\title{
Validation of Adolescent Anger Scale
}

\author{
T.L. Alaka Mani ${ }^{1 *}$ and Manoj Kumar Sharma \\ ${ }^{1}$ Research Scholar, SVYASA Yoga University, Karnataka, India \\ ${ }^{2}$ Department of Clinical Psychology, NIMHANS, Bengaluru, India \\ *Corresponding author
}

\begin{tabular}{|c|c|}
\hline & A B S T R A C T \\
\hline $\begin{array}{l}\text { Adolescent } \\
\text { Anger Scale, } \\
\text { STAXI-2-CA. }\end{array}$ & \multirow{3}{*}{$\begin{array}{l}\text { Anger is the most frequently and most commonly occurring phenomenon. Anger issues } \\
\text { during adolescence lead to many developmental issues and have lifelong impact. } \\
\text { Assessing anger at this stage is hence critical and important. Studies report anger } \\
\text { experience and expression vary with respect to age, gender and culture. A newly } \\
\text { developed adolescent anger scale by the author has been validated in this study. The newly } \\
\text { developed scale along with State Trait Anger Expression Inventory for Children and } \\
\text { Adolescent was administered to } 323 \text { Children in a survey study conducted in schools. The } \\
\text { newly developed adolescent anger is robust enough to assess anger expression and anger } \\
\text { experience in high school children. Results also suggest STAXI-2-CA can be used in } \\
\text { Indian Context with slight modification. Self reporting adolescent scale is in par with the } \\
\text { STAXI-2-CA in assessing anger experience and expression. }\end{array}$} \\
\hline Article Info & \\
\hline $\begin{array}{l}\text { Accepted: } \\
\text { 29 December } 2016 \\
\text { Available Online: } \\
\text { 10 January } 2017\end{array}$ & \\
\hline
\end{tabular}

\section{Introduction}

Anger related issues are on rise in schools and colleges across the globe. Anger is precursor for aggression, violence and many behavioural and conduct disorders (Hubbard, 2006; Lucia, 2015; Pullen, 2015). Aggressive behaviour during adolescence is considered as a risk factor for adulthood violence and criminal behaviour (Rowell, 2002).

Uncontrolled adolescent angeris a contributing factor for deaths due to homicide, suicide and injuries (CDC, 2015). Anger is associated with violence, cognitive distortion (Simona, 2012) and physical and verbal aggression (Rubio, 2016; Cornell, 1999). Intense, uncontrolled feelings of anger are often associated with externalizing behavior problems, particularly aggression (John, 2005).
Centre of Adolescent anger leading to violence is identified as a health disparity (CDC, 2012). Studies have documented significant association between anger and depression, stress (Pullen 2015; Zimmer, 2015; Deffenbacher, 1996) in adolescents; Association is also seen with suicidal attempts, conduct disorders, hyper tension, heart diseases, psychosomatic ailments (Dale, 2009; Stephanie, 2009; Ahmad, 2007; Grunbaum, 1997). Negative life events, anxiety and drug have shown significant positive correlations with anger in adolescents (Kathryn Puskar, 2008). Studies on premenstrual syndrome in adolescent girls reported high prevalence (59\%) of anger/ irritability as a most common symptom (Raval, 2015; Doerte, 2014). 
High trait anger in adolescence have shown negative relationship with health, social, and academic consequences (Colleen, 2014). Adolescents exposed to violence had poorer school performance and adjustment scores (Munni, 2006). Trait anger also has negative relationship with Self-esteem in adolescents and anger control has shown positive correlation with self-esteem (Coskun, 2009). Significant correlation is observed between trait anger and proneness to shame in youth (Jennie, 2011).

Studies on Indian adolescent population indicate a rise in anger related issuessuch as angry behaviours, bullying, aggression and violence. Study on adolescent violence reports $23 \%$ of victims and $13 \%$ perpetrators of violence (Munni, 2006) among 1500 Indian adolescents. In a survey conducted in many cities of India, reports $18 \%$ of 5476 youths shown high aggression scores. Higher angeraggression scores were observed in males than females and also in the age group of 1619 years (Sharma, 2015). Parental anger styles tend to have strong impact on anger expression in Indian adolescent females (Kavitha D, 2014). Aggression has shown negative correlation with interpersonal and romantic relationships among Indian youth (Sharma, 2013). Indian alcohol-dependent youths reported low levels of anger control, high level of trait anger and poor quality of life (Sharma, 2012).

Though the physiological activities during anger arousal is universal in its characteristics and behaviour, there exists variation in terms of its conceptualisation, perception and expression pattern (Potegal, 2010). Studies also indicate variation intra and intercultural context in addition to age and gender (Tara, 2015). This has led to emergence of several theories of anger and adolescent anger inventories (Kovecses, 2010). Most popular theory of anger is Spielberger's State-Trait anger taxonomy which is considered fundamental and widely adopted theory. Based on this theory an array of Anger Inventories has been developed for children, adolescents and adult population (Spielberger, 1988; Brunner, 2009). The scale has been adapted to many languages and many cultures.

Further available adolescent anger inventories appear to have the limitation of culture specificity and sensitivity as the words used to describe anger have variety of meaning in different cultures (e.g. word 'mad') (Alaka Mani, 2016). A review study reports these scales differ from another as they measure different aspects of anger (Burney, 2001). Further a review study on adolescent school anger states that the available psychometric adolescent anger scales do not represent the construct adequately or comprehensively (Mathew, 2008; Smith, 2006). Another study reports self-reporting questionnaires for anger must be adapted for cross-cultural usage and should not be back-translated (Moscoso, 2011).

Indian classical text provides enormous resource on the concepts on anger. According to the scriptures, anger is born out of Rajasic nature and is an internal enemy of man. Anger manifests at behavioral, verbal and mental level. Based on this principle the author of this paper has developed an adolescent anger scale which has shown significant reliability and validity scores. This study is to validate the newly developed scale with reference to well-structured STAXI-2-CA (State Trait Anger Expression Inventory for Children and Adolescents).

\section{Methods and Materials}

Design: It is school based survey conducted in high schools with one time data collection in groups. Consent to participate in the 
survey was obtained in writing by the children and approval obtained from school authorities. Authorised tools and software were used for measurements and assessment.

Sample: The participants include323 healthy adolescents (171 girls \& 152 boys) studying in $8^{\text {th }}, 9^{\text {th }}$ and $10^{\text {th }}$ standard in English medium private co-education high schools in south Bangalore. Inclusion criteria were ability to read, write and communicate in English while adolescents unwilling to participate were excluded.

Tool: Two self-reporting anger scales for adolescents were used. They are

1) Author developed Anger Scale: A 23 items, measuring anger at Kayena (behavioural), Vacha (speech) and Manasa (Mental) domains.

2) State-Trait Anger Expression InventoryChild and Adolescents (STAXI 2 CA scale): A 35 item self-report scale that measures anger experience, expression and control in adolescents.
In the STAXI -2-CA Scale, some of the terms like 'grumpy' 'grouchy' were difficult to understand by the children in the Indian cultural context. The meaning of such terms was explained to the group and also incorporated within brackets in the scale.

Both scales were administered in 3 schools. Children were briefed about the study and then asked to fill up the questionnaire. Children were instructed to answer all the questions and they took around 5-10 minutes for filling up the questionnaire.

\section{Analysis}

The scores of both the scales were tested for correlation. Pearson Correlation co-efficient value of $r=0.934$ indicate that the scales do not show significant different pattern while assessing anger in adolescents.

Mean and standard deviation was calculated for the scores of both the scales and tabulated in table 1 below:

Table.1

\begin{tabular}{|l|c|c|c|c|c|c|}
\hline & \multicolumn{2}{|c|}{ Boys } & \multicolumn{2}{c|}{ Girls } & \multicolumn{2}{c|}{ Total Scores } \\
\hline & Mean & SD & Mean & SD & Mean & SD \\
\hline Scale 1 & 39.95 & 5.76 & 40.66 & 5.43 & 40.33 & 5.59 \\
\hline Scale 2 & 63.87 & 8.71 & 64.82 & 7.83 & 64.38 & 8.26 \\
\hline
\end{tabular}

Scale 1: Newly developed scale \& Scale 2: is STAXI 2 CA Scale

Independent $t$ test was done to compare the mean scores of both the scales which showed a significant difference.

\section{Results and Discussion}

The newly developed scale established a good correlation coefficient value ( $\mathrm{r}=0.934)$ with respect to widely used STAXI-2-CA scale. However, independent $t$ test failed to validate this correlation. The scoring range for each scale was different and they are grounded on different theory of conceptualisation of anger. This could be the reason for getting the significant $p$ value. Comparison of Means and Standard Deviation showed a similar pattern of anger experience and expression in both the genders.

A prevalence study conducted by the author using STAXI 2 CA with Indian Adolescents 
observed that the children had difficulty in understanding a few items and words as they have a different meaning in the Indian social context (Alaka Mani, 2016). In both the studies, authors have found feasibility of STAXI-2-CA scale for administration in Indian adolescent population and strongly recommend adaptation of this well-structured scale to Indian context.

In conclusion, the newly developed adolescent anger scale showed good correlation with STAXI 2 CA Scale.

\section{References}

Ahmad Ghanizadeh. 2008. Ahmad Ghanizadeh; 'Gender difference of school anger dimensions and its prediction for suicidal behaviour in adolescents', Int. J. Clin. Health Psychol.

Alaka Mani, T.L,. Manoj Kumar Sharma, Marimuttu, P., Omkar, S.N., Nagendra, H.R. 2016. Anger assessment among high school children, Int. J. CMPR, Vol. 2, Issue, 8 pp.585-590, August, 2016.

Brunner. 2009. Brunner, T. M. \& Spielberger, C.D., The State Trait Anger Expression Inventory, Second edition, Child Adolescent (STAXI-C/A). Psychological Assessment Resources: Sarasota, Florida (2009).

Burney, D.M. 2001. DeAnna McKinnie Burney, Jeffrey Kromrey; Initial Development and Score Validation of the Adolescent Anger Rating Scale; Educational and Psychological Measurement, 61(3):446-460. doi:10.1177/0013164012 1971310

CDC. 2006. Centers for Disease Control [CDC]. Youth risk behavior surveillance - United States, 2005 Morbidity and Mortality Weekly report, 55 (SS-5). 2006. Retrieved March 23, 2007. http://www.cdc.gov/mmwr/PDF/SS/
SS5505.pdf

Colleen, A.Q. 2015. Colleen A. Quinn, David Rollock, and Scott R. Vrana 'A Test of Spielberger's State-Trait Theory of Anger with Adolescents: Five Hypotheses' NIH Public Access, Emotion. 2014 February, 14(1): 74-84. doi:10.1037/a0034031.

Cornell, D.G. 1999. Cornell DG, Peterson CS and Richards $\mathrm{H}$ 'Anger as a predictor of aggression among incarcerated adolescents', J. Consult Clin. Psychol., 67: $108-115$

Coskun, A. 2009. Coskun Ars1An; Anger, Self-eSteem, and Perceived Social Support in Adolescence; Social Behavior and Personality, 37(4), 555564.

Dale, J.T. 2009. Dale J Terasaki, Bizu Gelaye, Yemane Berhane and Michelle A Williams; 'Anger expression, violent behavior, and symptoms of depression among male college students in Ethiopia', BMC Public Health, 9: 13 doi:10.1186/1471-2458-9-13

Deffenbacher. 1996. Deffenbacher JL, Lynch, R. S., Oetting, E. R., \& Kemper, C. C. Anger reduction in early adolescents. $J$. Counseling Psychol., 43, 149- 157.

Douglas, C., Smith, Michael James Furlong, Peter Boman. 2006. Assessing anger and hostility in school settings; Research gate.

Grunbaum. 1997. Jo Anne Grunbaum, Sally W. Vernon, Carla M. Clasen;

The association between anger and hostility and risk factors for coronary heart disease in children and adolescents: A review; Annals of Behavioral Med., 19: 179 doi: 10.1007/BF02883335

Jennie, H. 2011. Jennie Hejdenberg, Bernice Andrews; The relationship between shame and different types of anger theory-based investigation; Personality and Individual Differences, 50: 1278- 
1282.

John, E.L. 2005. John E. Lochman, Nicole R. Powell, Nancy Clanton, Heather K. McElroy, book chapter 'Anger and Aggression.

Julie, A., Hubbard, Meghan, D., McAuliffe, Ronnie, M. Rubin, and Michael, T. Morrow; The Anger-Aggression Relation in Violent Children and Adolescents.

Kathryn Puskar. 2008. Kathryn Puskar, DianxuRen, Lisa Marie Bernardo, Tammy Haley and KirstiHetager Stark, 'anger correlated with psychosocial variables in rural youth, Compr. Pediatr. Nurs.

Kavitha, D. 2014. Kavitha Dhanaraj and R Manoj; 'A study on expression of anger among the parents and their adolescent daughters', Indian Streams Res. J.

Lucia Hernawati, Esti Rahayu, Petrus Soejowinoto. 2015. The Predictors of Indonesian Senior High School Students' Anger at School; J. Education and Practice, Vol.6, No.23.

Mamta, Nov Rattan Sharma. 2013. Across Gender Comparison in Anger Expression; Global International Research Thoughts.

Mathew, A.K. 2008. Matthew A. Kerr, Barry H. Schneider; Anger expression in children and adolescents: A review of the empirical literature, Clin. Psychol. Rev., 28: 559-577.

Michael Potegal, Gerhard Stemmler, Charles Spielberger. Editors of International Handbook on Anger - Springer Science, 2010, DOI 10.1007/978-0-387-89676-2

Manolete, S., Moscoso and Charles, D. 2011. Spielberger; Cross-cultural assessment of emotions: The expression of anger; Revista de Psicología Vol. 29(2), (ISSN 0254-9247).

Munni. 2006. Munni R, Malhi P: Adolescent violence exposure, gender issues and impact. Indian Paediatr., 43(7): 607-
612.

Pullen, L. 2015. Pullen L, Modrcin MA, McGuire SL, Lane K, Kearnely M, Engle S.; Anger in Adolescent Communities: How Angry Are They?; Pediatr Nurs., 41(3): 135-40.

Raval, C.M. 2016. Raval CM, Panchal BN, Tiwari DS, Vala AU and Bhatt RB; 'Prevalence of premenstrual syndrome and premenstrual dysphoric disorder among college students of Bhavnagar, Gujarat, Indian J. Psychiatry, 58(2):164-70. doi: 10.4103/0019. 5545.183796.

Reyes, L.R. 2003. Reyes LR, Meininger JC, Liehr P, Chan W, Mueller WH; Anger in adolescents: sex, ethnicity, age differences and psychometric properties; Nurs Res., 52(1): 2-11.

Rowell, H. 2002. L. Rowell Huesmann, Leonard D. Eron, and Eric F. Dubow; Childhood predictors of adult criminality: are all risk factors reflected in childhood aggressiveness?; Criminal Behaviour and Mental Health, 12, 185208.

Rubio, G.F. 2016. Rubio-Garay F, Carrasco MA, Amor PJ; 'Aggression, anger and hostility: evaluation of moral disengagement as a mediational process' Scand. J. Psychol.

Sharma, M.K. 2012. Sharma MK, LNSuman, Pratima Murthy and Palaniappan Marimuthu, State-Trait Anger and Quality of Life Among Alcohol Users, German J. Psychiatry.

Sharma, M.K. 2013. Sharma MK, Mohan Raju; 'Relationship of Personality Dimensions and aggression in romantic relationship among youth; Indian $J$. Psychol. Med.

Sharma, M.K. 2015. Manoj Kumar Sharma, Palaniappan, Marimuthu; Prevalence and Psychosocial Factors of Aggression Among Youth; Indian J. Psychol. Med., 36: $48-53$. 
Simona. 2012. Simona V Chereji, Sebastian Pintea and Daniel David; The Relationship of Anger and Cognitive Distortions with Violence in Violent Offenders Population: A Meta Analytic Review; The European J. Psychol. Appl. Legeal Context, 4(1): 59-77.

Spilberger, C.D. 1988. State-Trait Anger Expression Inventory (STAXI) professional mannual.Lutz FL; Psychological Assessment Resources.

Stephanie, S. 2009. Stephanie S. Daniel, Franklin, David B. Goldston, Alaattin Erkanli, Joseph $\mathrm{C}$ and Andrew $\mathrm{M}$. Mayfield; Trait Anger, Anger Expression, and Suicide Attempts among Adolescents and Young Adults: A Prospective Study, J. Clin. Child Adolesc. Psychol.

Tara, M. 2012. Chaplin, Amelia Aldao; Gender Differences in Emotion Expression in Children: A MetaAnalytic Review; Psychological Bulletin (c) 2012 American Psychological Assoc., Vol. 139, No. 4, 735-765 0033-2909/13/\$12.00 DOI: 10.1037/a0030737.

Victoria, d.B. 2004. Victoria del Barrio,
Anton Aluja and Charles Spielberger; Anger assessment with the STAXI-CA: psychometric properties of a new instrument for children and adolescents; Personality and Individual Differences, 37: 227-244.

Wongtongkam. 2013. Nualnong Wongtongkam, Paul Russell Ward, Andrew Day, Anthony Harold Winefield; Reliability and Validity of Self-Reported Questionnaires Related to Adolescent Violence and Consequences, Thailand, Int. J. Social Sci. Studies, Vol. 1, No. 2; October 2013; ISSN 23248033 E-ISSN 2324-8041.

Zimmer, G.M.J. 2015. Zimmer-Gembeck MJ, Skinner EA, 'Adolescent vulnerability and the distress of rejection: Associations of adjustment problems and gender with control, emotions, and coping' $J$. Adolesc., 45: 149-59. Epub 2015 Oct 3.

Zoltan, K. 2010. Zoltán Kövecses, CrossCultural Experience of Anger: A Psycholinguistic Analysis, Int. Handbook of Anger, DOI 10.1007/9780-387-89676-2010.

\section{How to cite this article:}

Alaka Mani, T.L., and Manoj Kumar Sharma. 2017. Validation of Adolescent Anger Scale. Int.J.Curr.Microbiol.App.Sci. 6(1): 659-664. doi: http://dx.doi.org/10.20546/ijcmas.2017.601.079 